\title{
The Association between Serum Vitamin D Concentration and Colon Polyp: A Cross-Sectional Study Using Health Care Screening Database in a Tertiary Hospital in Korea
}

\author{
Mun Young Yoo', Jungkwon Lee ${ }^{1, *}$, Ji In Chung ${ }^{2, *}$, Yohwan Yeo', In Young Cho ${ }^{3}$ \\ 'Department of Family Medicine, Samsung Medical Center, Sungkyunkwan University School of Medicine, Seoul, Korea \\ ${ }^{2}$ Department of Health Promotion Center, Samsung Medical Center, Sungkyunkwan University School of Medicine, Seoul, Korea \\ ${ }^{3}$ Department of Family Medicine, Kangbuk Samsung Hospital, Sungkyunkwan University School of Medicine, Seoul, Korea
}

Background: As indoor activity increases with modern lifestyles changes, reduced exposure to sunlight may lead to reduced vitamin D synthesis. Previous studies demonstrated that increased vitamin D level is associated with decreased risk of colon cancer; therefore, this study attempted to determine the association between vitamin D and colon polyps, which may be precancerous lesions, in participants who underwent colonoscopy exams.

Methods: A total of 31,004 participants who underwent routine health checkups, including vitamin D level and colonoscopy, at Samsung Medical Center in South Korea from 2010 to 2018 were included in the study. Colorectal polyps were diagnosed through biopsy after performing colonoscopy exams. Participants were categorized into three groups according to level of vitamin $\mathrm{D}$ (deficient: $<20 \mathrm{ng} / \mathrm{mL}$ ), insufficient: $20 \leq$ vitamin $\mathrm{D}<30 \mathrm{ng} / \mathrm{mL}$, and sufficient: $\geq 30 \mathrm{ng} / \mathrm{mL}$ ). We analyzed the presence of colorectal polyps according to vitamin D level, and performed multiple logistic regression analyses for the association between vitamin $\mathrm{D}$ level and colorectal polyps.

Results: About $50 \%$ of participants had colorectal polyps (hyperplastic polyp, $n=4,864$; adenomatous polyp, $\mathrm{n}=10,470$; adenocarcinoma, $\mathrm{n}=24$ ). There were no significant associations between vitamin $\mathrm{D}$ categories and colorectal polyp and colorectal cancer. However, when further analyzing by type of polyp, the risk of hyperplastic polyps significantly decreased with increasing vitamin $\mathrm{D}$ levels ( $\mathrm{P}$ for trend $=0.006$ ).

Conclusion: We did not find evidence for an association between vitamin D and overall colorectal polyps; however, we observed a trend for decreased odds of hyperplastic polyps with increased vitamin D levels in comparison to vitamin D deficient subjects.

Keywords: Vitamin D; Vitamin D Deficiency; Colonic Polyps; Adenomatous Polyps; Hyperplastic Polyp

Received: July 28, 2020, Revised: November 14, 2020, Accepted: December 3, 2020

${ }^{*}$ Corresponding Author: Jungkwon Lee https://orcid.org/0000-0001-5503-9605

Tel: +82-2-3410-2441, Fax: +82-2-3410-0388, E-mail: jklee@skku.edu

${ }^{*}$ Corresponding Author: Ji In Chung https://orcid.org/0000-0003-0894-3575

Tel: +82-2-3410-1476, Fax: +82-2-3410-0054, E-mail: jiin.chung@samsung.com

*These two corresponding authors contributed equally to this study as co-corresponding author. 


\section{INTRODUCTION}

Vitamin D is an essential hormone for calcium homeostasis, bone formation and maintenance, and mineral metabolism, and is an essential nutrient that plays a significant role in the prevention and treatment of osteoporosis. However, the lifestyle of modern people is changing and indoor activities are increasing. This change of lifestyle may lead to decrease in ultraviolet exposure, and thus reduction in vitamin D synthesis. ${ }^{1)}$

According to statistics published by the National Health Insurance Service in 2015 , it is estimated that about 18,000 people in Korea are treated for vitamin D deficiency. This figure increased more than 9 times from 2009 to 2013, and continues to increase. In Korea's National Health and Nutrition Survey in 2010, only $13.2 \%$ of men and $6.7 \%$ of women had sufficient vitamin D levels (more than $30 \mathrm{ng} / \mathrm{mL}$ ), and the majority had deficient or insufficient levels. ${ }^{1)}$

Several recent studies have shown that vitamin D deficiency is associated with some types of cancers ${ }^{2-4)}$ as well as chronic diseases such as hypertension, ${ }^{5)}$ diabetes, ${ }^{6)}$ cardiovascular diseases, ${ }^{7)}$ and autoimmune diseases. ${ }^{8)}$ In meta-analysis of retrospective studies, higher serum vitamin D levels were associated with lower risk of colorectal and breast cancer. ${ }^{3,4)}$ A meta-analysis of nine prospective cohort studies also showed that increase in vitamin D intake and serum 25-hydroxycholecalciferol $(25(\mathrm{OH}) \mathrm{D})$ levels reduced the risk of colorectal cancer incidence. ${ }^{9)}$ In addition, increased calcium intake, which is closely associated with vitamin $\mathrm{D}$, lowered the risk of developing colon and breast cancer. ${ }^{10)}$ Currently, there is a growing interest in vitamin D's function and its clinical value. Vitamin D may possibly exert cancer preventive effects by acting as a hormone that regulates cell growth.

Recently, the mechanism of colorectal cancer is thought to progress as an "adenoma to carcinoma transformation", which means conversion from colorectal adenomas to colorectal cancer. ${ }^{11)}$ There is an increasing interest in analyzing environmental risk factors that can affect this transformation. ${ }^{12)}$ Early detection and removal of colon polyps is an important preventive method of colon cancer, but primary prevention to prevent the occurrence of colon polyps may be achieved by managing risk factors.

In this study, we attempted to examine the association between vi- tamin D and colon polyps by analyzing serum vitamin D levels of participants who performed colonoscopy exams.

\section{METHODS}

\section{Study Population}

All adults who visited the Health Promotion Center at Samsung Medical Center in Korea and underwent routine health check-ups from January 2010 to December 2018 were eligible for this cross-sectional study. Individuals were excluded if they: (1) were previously or currently diagnosed with colorectal cancer; (2) did not have data on body mass index (BMI) (n=55); (3) did not answer questions on physical activity ( $\mathrm{n}=2,454)$, smoking history $(\mathrm{n}=1,448)$, alcohol history $(\mathrm{n}=86)$; or (4) did not provide an answer on aspirin or take non-steroid anti-inflammatory drugs (NSAIDs) intake $(n=1,923)$, which might affect vitamin D metabolism. As a result, we excluded 5,966 individuals with missing data. A total of 31,004 participants (21,000 male and 10,004 female) were analyzed (Figure 1). The Institutional Review Board of the Samsung Medical Center (IRB approval no., SMC 2019-09-045) approved this study and renounced the requirement for informed consent as we used only de-identified data routinely collected during health screening visits.

\section{Data Collection}

Most health check-up programs in this Health Promotion Center are based on both general health screening including national health screening for cardio-metabolic diseases and cancers according to national recommendation and on-demand individual screening. In Korea, subjects aged over 50 years and average-risk persons were recommended to receive colonoscopy exams every 5 years for secondary prevention of colorectal cancer. ${ }^{13)}$ Subjects who have any symptoms including bowel habit change or weight loss, or who want to be examined can also choose to perform colonoscopy in this health-care center. There is insufficient evidence demonstrating benefits of screening for vitamin D deficiency at a population level. In the absence of this evidence, at this time, 25(OH)D measurement is reasonable in groups of people at high risk for vitamin D deficiency and in whom an immediate response to optimization of vitamin D status could be expect-

All adults who visited the Samsung Medical Center Health Promotion Center and underwent comprehensive health checkup examinations including serum vitamin D \& colonoscopy between January 1, 2010, and December 31, 2018 $(n=36,970)$

\begin{tabular}{|l|} 
Exclusions $(\mathbf{n}=\mathbf{5 , 9 6 6 )}$ \\
Who did not measure height and weight for body mass index $(n=55)$ \\
Who did not answer about physical activity $(n=2,454)$ \\
Who did not answer about smoking history $(n=86)$ \\
Who did not answer about alcohol history $(n=86)$ \\
Who did not answer on a spirin or NSAIDs intake $(n=1,923)$
\end{tabular}

Participants included in this analysis $(n=31,004)$

Figure 1. Flowchart of study participants. NSAIDs, non-steroidal anti-inflammatory drugs. 
ed. ${ }^{14)}$ But with the increasing importance of vitamin D, the programs of this Health Promotion Center include blood tests for vitamin D levels regardless of age.

A standardized self-administered questionnaire and a comprehensive physical examination were performed. The questionnaire included questions about physical activity, family history, smoking status, alcohol consumption, medication use, and medical or surgical history. Physical activity was assessed by using the simple form of the International Physical Activity Questionnaire. Participants were required to answer questionnaires regarding whether they have family history of colorectal cancer or not. Smoking status was categorized into never, former, or current smoker. Former smokers were those who did not currently smoke but had smoked in the past. Current alcohol consumption was categorized into none or moderate $(<30 \mathrm{~g} / \mathrm{d}$ in men and $<20 \mathrm{~g} / \mathrm{d}$ in women). BMI was calculated as weight in kilograms divided by height in squared meters. BMI was categorized into underweight (BMI $\left.<18.5 \mathrm{~kg} / \mathrm{m}^{2}\right)$, normal $\left(18.5 \mathrm{~kg} / \mathrm{m}^{2} \leq \mathrm{BMI}<23.0 \mathrm{~kg} / \mathrm{m}^{2}\right)$, overweight $\left(23.0 \mathrm{~kg} / \mathrm{m}^{2} \leq\right.$ BMI $\left.<25.0 \mathrm{~kg} / \mathrm{m}^{2}\right)$, and obese (BMI $\left.\geq 25.0 \mathrm{~kg} / \mathrm{m}^{2}\right)$. Blood samples were collected after $>8$ hours of fasting. Participants were required to answer questionnaires on whether they regularly take aspi-

Table 1. Baseline characteristics of the study population

\begin{tabular}{|c|c|c|c|c|}
\hline \multirow{2}{*}{ Characteristic } & \multirow{2}{*}{ Total $(\mathrm{N}=31,004)$} & \multicolumn{2}{|c|}{ Presence of polyp } & \multirow{2}{*}{ P-value* } \\
\hline & & No $(n=15,258)$ & Yes $(n=15,746)$ & \\
\hline Age (y) & $53.3 \pm 9.5$ & $51.3 \pm 9.7$ & $55.2 \pm 9.0$ & $<0.001$ \\
\hline \multicolumn{5}{|l|}{ Sex } \\
\hline Male & $21,000(67.7)$ & $9,108(59.7)$ & $11,892(75.5)$ & $<0.001$ \\
\hline Female & $10,004(32.3)$ & $6,150(40.3)$ & $3,854(24.5)$ & \\
\hline Body mass index $\left(\mathrm{kg} / \mathrm{m}^{2}\right)$ & $24.0 \pm 3.1$ & $23.6 \pm 3.1$ & $24.5 \pm 3.0$ & $<0.001$ \\
\hline Underweight (BMl <18.5) & $790(2.6)$ & $567(3.7)$ & $223(1.4)$ & $<0.001$ \\
\hline Normal $(18.5 \leq \mathrm{BMl}<23.0)$ & $10,528(34.0)$ & $5,996(39.3)$ & $4,532(28.8)$ & \\
\hline Overweight $(23.0 \leq \mathrm{BMl}<25.0)$ & $8,514(27.5)$ & $4,012(26.3)$ & 4,502 (28.6) & \\
\hline Obesity (BMl $\geq 25.0)$ & $11,172(36.0)$ & $4,683(30.7)$ & $6,489(41.2)$ & \\
\hline Physical activity & & & & 0.085 \\
\hline No exercise & 1,058 (3.4) & $511(3.4)$ & $547(3.5)$ & \\
\hline $1-2$ days per week & $10,741(34.6)$ & $5,189(34.0)$ & $5,552(35.3)$ & \\
\hline 3-4 days per week & $12,206(39.4)$ & $6,054(39.7)$ & $6,152(39.1)$ & \\
\hline More than 5 days per week & 6,999 (22.6) & $3,504(23.0)$ & $3.495(22.2)$ & \\
\hline Family history of colorectal cancer & & & & 0.058 \\
\hline No & $28,669(92.5)$ & $14,153(92.8)$ & $14,516(92.2)$ & \\
\hline Yes & $2,335(7.5)$ & 1,105 (7.2) & $1,230(7.8)$ & \\
\hline Smoking habits & & & & $<0.001$ \\
\hline Non-smoker & $14,531(46.9)$ & $8,428(55.2)$ & 6,103 (38.8) & \\
\hline Ex-smoker & $9,811(31.6)$ & $4,314(28.3)$ & $5,497(34.9)$ & \\
\hline Current smoker & $6,662(21.5)$ & $2,516(16.5)$ & $4,146(26.3)$ & \\
\hline Alcohol drinking & & & & $<0.001$ \\
\hline Non-drinker & $7,487(24.2)$ & 4,025 (26.4) & $3,462(22.0)$ & \\
\hline Drinker & $23,517(75.9)$ & $11,233(73.6)$ & $12,284(78.0)$ & \\
\hline Regular aspirin or NSAIDs use & & & & $<0.001$ \\
\hline No & $26,282(84.8)$ & $13,218(86.6)$ & 13,064 (83.0) & \\
\hline Yes & $4,722(15.2)$ & $2,040(13.4)$ & $2,682(17.0)$ & \\
\hline Vitamin D concentration $^{\dagger}$ & & & & $<0.001$ \\
\hline Deficient & $19,218(62.0)$ & $9.702(63.6)$ & $9.516(60.4)$ & \\
\hline Insufficient & $8,786(28.3)$ & $4,121(27.0)$ & $4,665(29.6)$ & \\
\hline Sufficient & $3,000(9.7)$ & $1,435(9.4)$ & $1,565(9.9)$ & \\
\hline 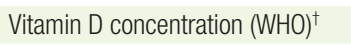 & & & & $<0.001$ \\
\hline Deficient & $3,579(11.5)$ & $1,974(12.9)$ & $1,605(10.2)$ & \\
\hline Insufficient & $15,639(50.4)$ & $7,728(50.7)$ & $7,911(50.2)$ & \\
\hline Sufficient & $11,786(38.0)$ & $5,556(36.4)$ & $6,230(39.6)$ & \\
\hline Vitamin D concentration $(\mathrm{IOM})^{\ddagger}$ & & & & $<0.001$ \\
\hline Deficient & 6,398 (20.3) & $3,375(22.1)$ & 2,923 (18.6) & \\
\hline Insufficient & $12,920(41.7)$ & $6,327(41.5)$ & $6,593(41.9)$ & \\
\hline Sufficient & $11,786(38.0)$ & $5,556(36.4)$ & $6,230(39.6)$ & \\
\hline
\end{tabular}

Values are presented as mean \pm standard deviation or number (\%).

NSAIDs, non-steroidal anti-inflammatory drugs; WHO, World Health Organization; IOM, Institute of Medicine.

${ }^{*}$ Serum levels of vitamin D were categorized into three groups: deficient (vitamin $\left.D<20 \mathrm{ng} / \mathrm{mL}\right)$, insufficient ( $20 \leq$ vitamin $\left.\mathrm{D}<30 \mathrm{ng} / \mathrm{mL}\right)$, and sufficient $(30 \mathrm{ng} / \mathrm{mL} \leq$ vitamin $\mathrm{D})$. ${ }^{\dagger}$ Vitamin D levels by WHO criteria: deficient $(<10 \mathrm{ng} / \mathrm{mL}$ ), insufficient ( $10 \leq$ vitamin $\mathrm{D}<20 \mathrm{ng} / \mathrm{mL})$, and sufficient $(\geq 20 \mathrm{ng} / \mathrm{mL})$. ${ }^{*}$ Vitamin D levels by IOM criteria: deficient $(<12$ $\mathrm{ng} / \mathrm{mL})$, insufficient (12 vitamin $\mathrm{D}<20 \mathrm{ng} / \mathrm{mL})$, and sufficient $(\geq 20 \mathrm{ng} / \mathrm{mL})$. 
rin, and whether they take NSAIDs.

Serum 25(OH)D levels for the three different types of vitamin D (D2, D3, and total) were measured by liquid chromatography-tandem mass spectrometry as a reference method to accurately estimate vitamin D status. For this analysis, the sum of 25(OH)D2 and 25(OH)D3 above the detection limit are reported as $25(\mathrm{OH}) \mathrm{D}$ concentrations. ${ }^{15)}$ Finally, participants were classified by serum concentrations of 25(OH)D into one of the three categories: deficient (vitamin $\mathrm{D}<20 \mathrm{ng} /$ $\mathrm{mL}$ ), insufficient ( $20 \leq$ vitamin $\mathrm{D}<30 \mathrm{ng} / \mathrm{mL}$ ), and sufficient (30 ng/ $\mathrm{mL} \leq$ vitamin $\mathrm{D}$ ). The main outcome of interest were findings from the colonoscopy exams including pathology reports, specifically the detection of colorectal polyps. Detailed data regarding polyp characteristics such as number, location, and histology were collected. Tissue biopsy results for "adenomatous polyp" or "hyperplastic polyp" of any grade were defined as colorectal polyps. Biopsy showing results for colorectal adenocarcinoma were defined as such.

\section{Statistical Analysis}

The presence of any colorectal polyp was analyzed as a binary variable by chi-square test according to individual vitamin $\mathrm{D}$ level. The association between serum 25(OH)D and colon polyp was estimated by multiple logistic regression. The odds ratios (ORs) for colon polyps were adjusted for covariates including age, sex, BMI, physical activity, family history of colorectal cancer, current smoking, drinking habits, and regular use of aspirin or NSAIDs. All analyses were conducted by Stata ver. 14.0 (Stata Corp., College Station, TX, USA).

\section{RESULTS}

Among 31,004 participants, the baseline characteristics of study participants by presence of polyp, are described in Table 1. According to the presence of polyp, no colonic polyp was found in 15,258 and polyp were found in 15,746. Mean age \pm standard deviation for each group was $51.3 \pm 9.7$ years in no presence of polyp group, $55.2 \pm 9.0$ years in the presence of polyp group $(\mathrm{P}<0.001)$. In both groups, more than about $60 \%$ of subjects were male $(\mathrm{P}<0.001)$. In the presence of polyp group, there were relatively more obese persons (BMI $\geq 25.0$ ) (30.7\% versus $41.2 \%$, respectively). Also, there are more polyp groups in smoking and regular aspirin or NSAIDs using group, statistically significant figures.

Table 2 shows the prevalence of colorectal polyps during the study period according to vitamin D levels. Of 31,004 people, 15,746 (50.8\%), each type of polyp (hyperplastic polyp, adenomatous polyp, and adenocarcinoma) was identified as having polyps after colonoscopy and biopsy. There was a significant difference among the groups according to vitamin $\mathrm{D}$ levels $(\mathrm{P}<0.001)$.

Table 3 lists ORs and 95\% confidence intervals (CIs) for colorectal polyps according to vitamin D levels. Compared to participants with vitamin D deficiency, the ORs (95\% CIs) of hyperplastic polyps suggested an inverse association between serum 25(OH)D (crude OR [cOR], 0.90; 95\% CI, 0.84-0.97 for the insufficient group and cOR, 0.91; 95\% CI, 0.88-1.03 for the sufficient group, respectively). The risk reduction of hyperplastic polyps remained significant in multiple logistic regression adjusted for selected variable (adjusted OR [aOR], 0.90; 95\%

Table 2. Presence of polyps according to vitamin D levels

\begin{tabular}{|c|c|c|c|c|c|}
\hline \multirow{2}{*}{ Variable } & \multirow{2}{*}{ Total $(\mathrm{N}=31,004)$} & \multicolumn{3}{|c|}{ Vitamin D concentration* } & \multirow{2}{*}{ P-value } \\
\hline & & Deficient $(n=19,218)$ & Insufficient $(\mathrm{n}=8,768)$ & Sufficient $(n=3,000)$ & \\
\hline Presence of polyp & & & & & $<0.001$ \\
\hline No & $15,258(49.2)$ & $9,702(50.5)$ & $4,121(46.9)$ & $1,435(47.8)$ & \\
\hline Yes & $15,746(50.8)$ & $9,516(49.5)$ & 4,665 (53.1) & $1,565(52.2)$ & \\
\hline Hyperplastic polyp & 4,864 (15.7) & $3,075(16.0)$ & $1,347(15.3)$ & $442(14.7)$ & 0.115 \\
\hline Adenomatous polyp & $10,470(33.8)$ & $6,249(32.5)$ & $3,164(36.0)$ & $1,057(35.2)$ & $<0.001$ \\
\hline Adenocarcinoma & $24(0.1)$ & $16(0.1)$ & $5(0.1)$ & $3(0.1)$ & 0.684 \\
\hline
\end{tabular}

Values are presented as number (\%).

*Serum levels of vitamin D were categorized into three groups: deficient (vitamin $D<20 \mathrm{ng} / \mathrm{mL}$ ), insufficient ( $20 \leq$ vitamin $\mathrm{D}<30 \mathrm{ng} / \mathrm{mL})$, and sufficient ( $30 \mathrm{ng} / \mathrm{mL} \leq$ vitamin $\mathrm{D})$. tEstimated by chi-square tests.

Table 3. Adjusted odds ratios and 95\% confidence intervals for colorectal polyps according to vitamin D levels

\begin{tabular}{|c|c|c|c|c|c|c|}
\hline \multirow{3}{*}{ Presence of polyp } & \multicolumn{5}{|c|}{ Vitamin D concentration* } & \multirow{3}{*}{ P for trend } \\
\hline & \multirow{2}{*}{ Deficient } & \multicolumn{2}{|c|}{ Insufficient } & \multicolumn{2}{|c|}{ Sufficient } & \\
\hline & & COR $(95 \% \mathrm{Cl})$ & $\mathrm{aOR}^{\dagger}(95 \% \mathrm{Cl})$ & $\operatorname{cOR}(95 \% \mathrm{Cl})$ & $\mathrm{aOR} \mathrm{R}^{\dagger}(95 \% \mathrm{Cl})$ & \\
\hline Polyp & 1 (Ref) & $1.15(1.10-1.21)$ & $0.98(0.93-1.04)$ & $1.11(1.03-1.20)$ & $0.95(0.88-1.03)$ & 0.200 \\
\hline Hyperplastic polyp & 1 (Ref) & $0.95(0.89-1.02)$ & $0.90(0.84-0.97)$ & $0.91(0.81-1.01)$ & $0.91(0.81-1.02)$ & 0.006 \\
\hline Adenomatous polyp & 1 (Ref) & $1.17(1.11-1.23)$ & $1.00(0.94-1.05)$ & $1.13(1.04-1.22)$ & $0.95(0.87-1.03)$ & 0.293 \\
\hline Adenocarcinoma & 1 (Ref) & $0.68(0.25-1.87)$ & $0.56(0.20-1.55)$ & $1.20(0.35-4.13)$ & $0.77(0.22-2.71)$ & 0.413 \\
\hline
\end{tabular}

COR, crude odds ratios; $\mathrm{Cl}$, confidence interval; aOR, adjusted odds ratio; Ref, reference.

${ }^{*}$ Serum level of vitamin $D$ were categorized into three groups: deficient (vitamin $D<20 \mathrm{ng} / \mathrm{mL}$ ), insufficient ( $20 \leq$ vitamin $\mathrm{D}<30 \mathrm{ng} / \mathrm{mL}$ ), and sufficient $(30 \mathrm{ng} / \mathrm{mL} \leq$ vitamin $\mathrm{D})$. ${ }^{\dagger}$ Estimated by multiple logistic regression adjusted for age, sex, body mass index, physical activity, family history of colorectal cancer, smoking habits, alcohol drinking, and regular intake of aspirin or non-steroidal anti-inflammatory drugs. 埗 for trend for aORs. 
CI, 0.84-0.97 and aOR, 0.91; 95\% CI, 0.81-1.02, respectively) with significant dose-response relationship (P-trend=0.006). In case of adenomatous polyps, compared to participants with vitamin D deficiency, the OR for risk increased to 1.17 (95\% CI, 1.11-1.23) for those with insufficient vitamin D levels, and to 1.13 (95\% CI, 1.04-1.22) for participants with sufficient vitamin D levels. However, there was no significant association between each group of vitamin $\mathrm{D}$ and adenomatous polyps after adjusting for selected variables (aOR, 1.00; 95\% CI, 0.941.05 for the insufficient group and aOR, 0.95; 95\% CI, 0.87-1.03 for the sufficient group). This showed similar patterns of results even if World Health Organization (WHO) and Institute of Medicine (IOM)'s standards for vitamin D levels changed (Supplementary Tables 1, 2). Subgroup analyses were also done for sex, and by BMI categories which were categorized into two groups (underweight-normal, BMI $<23.0$ $\mathrm{kg} / \mathrm{m}^{2}$; overweight-obese, $\mathrm{BMI} \geq 23.0 \mathrm{~kg} / \mathrm{m}^{2}$ ). Results were consistent for hyperplastic polyp in men and in both BMI categories, except women, whose number of study participants were relatively small (N=1,148) (Supplementary Table 3).

\section{DISCUSSION}

In this large cross-sectional study, there was no association between vitamin D levels and colorectal polyps, and adenocarcinomas found through colonoscopy exams during routine health examinations, except for hyperplastic polyps. To our knowledge, this is the first study to examine the association of vitamin D levels with both colorectal hyperplastic polyps and adenomatous polyps in a large population. This showed similar patterns of results even if WHO and IOM's standards for vitamin D levels changed.

Contrary to this study, a cross-sectional study of adenoma and hyperplastic polyps among 459 Americans of an integrated health plan evaluated via colonoscopy revealed a significant inverse association between vitamin $\mathrm{D}$ concentration and colorectal adenomas, but not hyperplastic polyps. ${ }^{15)}$ The majority of other studies have also reported an inverse association between 25(OH)D levels and colon adenomatous polyps. ${ }^{16-18)}$ Whereas another study showed null results, consistent with our study's results, in a predominantly white male, healthy population presenting for routine colonoscopy screening, which reported that serum vitamin D levels were not associated with increased adenomatous polyps detection. ${ }^{19)}$ Meta-analyses of serum 25(OH)D and colorectal adenomas have shown a significant inverse relationship for adenoma incidence, ${ }^{3,20)}$ but not for the recurrence of colorectal polyps. Another study also found no association between measured 25(OH)D and overall recurrence of colorectal adenomatous polyps, but there was a meaningful direct association between the vitamin $D$ metabolite and the recurrence of $\geq 3$ adenomatous polyps. ${ }^{16)}$ One case-control study of 112 Korean adults found an inverse association between circulating serum vitamin D levels and colorectal adenoma in women but not in men, ${ }^{17)}$ possibly via crosstalk between the vitamin D receptor and the estrogen receptor as presented by Cross et al. ${ }^{21)}$ However, recent studies have found no gender differences between vitamin $\mathrm{D}$ level and colorectal polyps. ${ }^{18,22)}$ Considering increased risk of colorectal cancer observed in epidemiologic studies and the pathophysiology of colorectal cancer and colorectal polyps (especially for adenomatous polyps), further longitudinal population-based studies are still needed to conclude the inconsistency among these studies.

Experimental studies have shown that 1,25(OH)2D suppresses cellular proliferation, leads differentiation and apoptosis, and suppresses angiogenesis. ${ }^{23,24)}$ In an in vitro study, colonic tumor tissues expressed a lower vitamin D receptor level than did normal tissues, and the tumor with a higher vitamin $\mathrm{D}$ receptor level was more responsive to $1,25(\mathrm{OH}) 2 \mathrm{D} .{ }^{25)}$ Additionally, the administration of 1,25(OH)2D or vitamin $\mathrm{D}$ analogues lead the expression of genes involved in cell differentiation. ${ }^{26,27)}$ But there is still the possibility of chance detection, since vitamin D levels are constantly changing, and do not reflect the average value over a sustained period. Moreover, serum vitamin $\mathrm{D}$ has been reported to be sensitive to seasonal changes, declining from November to March, which is related to decreased endogenous synthesis in the skin with less exposure to sunlight. ${ }^{19)}$ Future studies should contain a detailed analysis of the contributors to circulating concentrations of vitamin $\mathrm{D}$, as well as the degree to which vitamin $\mathrm{D}$ may be associated with the development of colorectal polyps. Furthermore, genetic variation in the vitamin D pathway is worthy of being assessed for any amendment of the association between the vitamin $\mathrm{D}$ metabolites and the development of colorectal polyps.

Compared to previous studies, strengths of our study include the large size of the study population, which included more than 30,000 participants with colonoscopy results and colorectal polyp characteristics proven by biopsy, and measurement of vitamin D concentrations. Second, we were able to identify both hyperplastic polyps and adenomatous polyps in the same population, and our results reproduce the well-characterized relationship between vitamin $\mathrm{D}$ and colorectal polyps, increasing our confidence in the findings. Third, the majority of previous studies have analyzed adenomatous polyps and vitamin $\mathrm{D}$, and only few studies have concurrently analyzed hyperplastic polyps in a large scale, as in our study.

There are some limitations to our study. First, because vitamin D and calcium are metabolically interrelated ${ }^{28)}$ it is important to consider whether the association between 25(OH)D levels and colorectal adenoma varied by calcium intake. However, information on individual calcium intake was not available in this study. Second, information on the prevalence of colorectal polyps before enrollment in this study is unavailable. Third, since our research is based on the health checkups conducted at the Health Promotion Center, the possibility of selection bias exists, with the inclusion of study participants with higher socioeconomic status and limited time for outdoor activities. Fourth, the data for the size and dysplasia of hyperplastic and adenomatous polyps were unavailable which were important findings of polyps according to their risk of cancer progression. Finally, residual confounding factors that we were unable to assess may have influenced our study's outcomes.

We found no association between vitamin D concentration and 
colorectal polyps and adenocarcinomas. However, higher serum vitamin D levels were associated with lower risk for the subtype of hyperplastic polyps. Further epidemiologic studies of longitudinal design are needed to clear this association taking into account the perspectives covered in this study.

\section{CONFLICT OF INTEREST}

No potential conflict of interest relevant to this article was reported.

\section{ACKNOWLEDGMENTS}

This study was performed using the database from the Health Promotion Center of Samsung Medical Center, and the results do not necessarily indicate the opinion of the Health Promotion Center of Samsung Medical Center.

\section{SUPPLEMENTARY MATERIALS}

Supplementary materials can be found via https://doi.org/10.4082/ kjfm.20.0181. Supplementary Table 1. Colorectal polyps according to vitamin D levels by World Health Organization criteria. Supplementary Table 2. Colorectal polyps according to vitamin D levels by Institute of Medicine criteria. Supplementary Table 3. Subgroup analysis of colorectal polyps according to vitamin D levels.

\section{ORCID}

Mun Young Yoo: https://orcid.org/0000-0003-2303-2075

Jungkwon Lee: https://orcid.org/0000-0001-5503-9605

Ji In Chung: https://orcid.org/0000-0003-0894-3575

Yohwan Yeo: https://orcid.org/0000-0002-1379-0510

In Young Cho: https://orcid.org/0000-0002-6240-9026

\section{REFERENCES}

1. Nah EH, Kim S, Cho HI. Vitamin D levels and prevalence of vitamin d deficiency associated with sex, age, region, and season in Koreans. Lab Med Online 2015;5:84-91.

2. Gandini S, Boniol M, Haukka J, Byrnes G, Cox B, Sneyd MJ, et al. Metaanalysis of observational studies of serum 25-hydroxyvitamin D levels and colorectal, breast and prostate cancer and colorectal adenoma. Int J Cancer 2011;128:1414-24.

3. Yin L, Grandi N, Raum E, Haug U, Arndt V, Brenner H. Meta-analysis: longitudinal studies of serum vitamin $\mathrm{D}$ and colorectal cancer risk. Aliment Pharmacol Ther 2009;30:113-25.

4. Chen P, Hu P, Xie D, Qin Y, Wang F, Wang H. Meta-analysis of vitamin $\mathrm{D}$, calcium and the prevention of breast cancer. Breast Cancer Res Treat 2010;121:469-77.

5. Naghshtabrizi B, Borzouei S, Bigvand P, Seifrabiei MA. Evaluation of the relationship between serum 25-hydroxy vitamin D and hypertension in Hamadan, Iran: a case control study. J Clin Diagn Res 2017;11:
LC01-3.

6. Lips P, Eekhoff M, van Schoor N, Oosterwerff M, de Jongh R, Krul-Poel $\mathrm{Y}$, et al. Vitamin D and type 2 diabetes. J Steroid Biochem Mol Biol 2017;173:280-5.

7. Leu Agelii M, Lehtinen-Jacks S, Zetterberg H, Sundh V, Bjorkelund C, Lissner L. Low vitamin D status in relation to cardiovascular disease and mortality in Swedish women: effect of extended follow-up. Nutr Metab Cardiovasc Dis 2017;27:1143-51.

8. Harrison SR, Li D, Jeffery LE, Raza K, Hewison M. Vitamin D, autoimmune disease and rheumatoid arthritis. Calcif Tissue Int 2020;106:5875.

9. Ma Y, Zhang P, Wang F, Yang J, Liu Z, Qin H. Association between vitamin D and risk of colorectal cancer: a systematic review of prospective studies. J Clin Oncol 2011;29:3775-82.

10. Pufulete M. Intake of dairy products and risk of colorectal neoplasia. Nutr Res Rev 2008;21:56-67.

11. Morimoto LM, Newcomb PA, Ulrich CM, Bostick RM, Lais CJ, Potter JD. Risk factors for hyperplastic and adenomatous polyps: evidence for malignant potential? Cancer Epidemiol Biomarkers Prev 2002; 11(10 Pt 1):1012-8.

12. Lee HM, Lee S, Lim JK, Seo JW, Lee KS, Baek SC, et al. Relationship of colorectal polyps and the risk factors including obesity, age, alcohol and smoking. Chonnam Med J 2009;45:168-74.

13. Kim Y. Colorectal cancer screening. Korean J Fam Pract 2013;3:139-46.

14. Holick MF, Binkley NC, Bischoff-Ferrari HA, Gordon CM, Hanley DA, Heaney RP, et al. Evaluation, treatment, and prevention of vitamin D deficiency: an Endocrine Society clinical practice guideline. J Clin Endocrinol Metab 2011;96:1911-30.

15. Adams SV, Newcomb PA, Burnett-Hartman AN, White E, Mandelson MT, Potter JD. Circulating 25-hydroxyvitamin-D and risk of colorectal adenomas and hyperplastic polyps. Nutr Cancer 2011;63:319-26.

16. Jacobs ET, Hibler EA, Lance P, Sardo CL, Jurutka PW. Association between circulating concentrations of 25(OH)D and colorectal adenoma: a pooled analysis. Int J Cancer 2013;133:2980-8.

17. Choi YJ, Kim YH, Cho CH, Kim SH, Lee JE. Circulating levels of vitamin $\mathrm{D}$ and colorectal adenoma: a case-control study and a meta-analysis. World J Gastroenterol 2015;21:8868-77.

18. Fedirko V, Bostick RM, Goodman M, Flanders WD, Gross MD. Blood 25-hydroxyvitamin D3 concentrations and incident sporadic colorectal adenoma risk: a pooled case-control study. Am J Epidemiol 2010;172:489-500.

19. Bryce C. Association of 25-OH vitamin D status with findings on screening colonoscopy. Mil Med 2018;183(suppl_1):547-51.

20. Wei MY, Garland CF, Gorham ED, Mohr SB, Giovannucci E. Vitamin D and prevention of colorectal adenoma: a meta-analysis. Cancer Epidemiol Biomarkers Prev 2008;17:2958-69.

21. Cross HS, Kallay E, Lechner D, Gerdenitsch W, Adlercreutz H, Armbrecht HJ. Phytoestrogens and vitamin D metabolism: a new concept for the prevention and therapy of colorectal, prostate, and mammary carcinomas. J Nutr 2004;134:1207S-1212S.

22. Yamaji T, Iwasaki M, Sasazuki S, Sakamoto H, Yoshida T, Tsugane S. Association between plasma 25-hydroxyvitamin D and colorectal adenoma according to dietary calcium intake and vitamin $\mathrm{D}$ receptor polymorphism. Am J Epidemiol 2012;175:236-44.

23. Holt PR, Arber N, Halmos B, Forde K, Kissileff H, McGlynn KA, et al. 
Colonic epithelial cell proliferation decreases with increasing levels of serum 25-hydroxy vitamin D. Cancer Epidemiol Biomarkers Prev 2002;11:113-9.

24. Deeb KK, Trump DL, Johnson CS. Vitamin D signalling pathways in cancer: potential for anticancer therapeutics. Nat Rev Cancer 2007;7: 684-700.

25. Shabahang M, Buras RR, Davoodi F, Schumaker LM, Nauta RJ, Evans SR. 1,25-Dihydroxyvitamin D3 receptor as a marker of human colon carcinoma cell line differentiation and growth inhibition. Cancer Res 1993;53:3712-8.
26. Chen A, Davis BH, Bissonnette M, Scaglione-Sewell B, Brasitus TA. 1,25-Dihydroxyvitamin $\mathrm{D}(3)$ stimulates activator protein-1-dependent Caco-2 cell differentiation. J Biol Chem 1999;274:35505-13.

27. Fernandez-Garcia NI, Palmer HG, Garcia M, Gonzalez-Martin A, del Rio M, Barettino D, et al. 1alpha,25-Dihydroxyvitamin D3 regulates the expression of Id 1 and Id2 genes and the angiogenic phenotype of human colon carcinoma cells. Oncogene 2005;24:6533-44.

28. Heaney RP. Vitamin D and calcium interactions: functional outcomes. Am J Clin Nutr 2008;88:541S-544S. 